\title{
Brazil nut sorting for aflatoxin prevention: a comparison between automatic and manual shelling methods
}

\author{
Ariane Mendonça $\mathrm{PACHECO}^{1}$, Maristela MARTINS ${ }^{1 *}$
}

\begin{abstract}
The impact of automatic and manual shelling methods during manual/visual sorting of different batches of Brazil nuts from the 2010 and 2011 harvests was evaluated in order to investigate aflatoxin prevention. The samples were tested as follows: in-shell, shell, shelled, and pieces in order to evaluate the moisture content $(\mathrm{mc})$, water activity $(\mathrm{Aw})$, and total aflatoxin $(\mathrm{LOD}=0.3 \mu \mathrm{g} / \mathrm{kg}$ and LOQ $0.85 \mu \mathrm{g} / \mathrm{kg}$ ) at the Brazil nut processing plant. The results of aflatoxins obtained for the manually shelled nut samples ranged from 3.0 to $60.3 \mu \mathrm{g} / \mathrm{g}$ and from 2.0 to $31.0 \mu \mathrm{g} / \mathrm{g}$ for the automatically shelled samples. All samples showed levels of mc below the limit of 15\%; on the other hand, shelled samples from both harvests showed levels of Aw above the limit. There were no significant differences concerning the manual or automatic shelling results during the sorting stages. On the other hand, the visual sorting was effective in decreasing the aflatoxin contamination in both methods.
\end{abstract}

Keywords: Bertholletia; water activity; moisture.

\section{Introduction}

Brazil nut (Bertholletia excelsa H.B.K) is a highly nutritious fruit from the Amazon region with significant economic importance (INSTITUTO..., 2010; COSTA et al., 2010). The production of Brazil nut, one of the main export products of the Amazon region, increased by $7.7 \%$ (40.357 tons) in 2010 and it maintained high growth rate in the last three years. This variation occurs due to the high demand for the product, mainly by companies linked to foreign trade. In Brazil, the Amazon State is the main producer (16.039 tons), followed by the states of Acre (12.362 tons) and Para (8.128 tons), according to Brazilian official data (INSTITUTO..., 2010).

However, Brazil nuts are associated with aflatoxin contamination, a carcinogenic metabolite. This contamination seems to prevent export to countries or regions where there is a strict aflatoxin limits, for example, European Union countries. As a consequence, the Brazil nut processing industries started trading in new markets such as Vietnam, China, and Australia (PACHECO; SCUSSEL, 2009).

On the other hand, the association of aflatoxin contamination with Brazil nut is not only a commercial concern, but also a public health concern since the nuts are processed in specific environmental conditions, that is, similar to those of the Amazon Region with temperatures $>30^{\circ} \mathrm{C}$ and relative humidity $(\mathrm{RH} \%)>70 \%$.

Other aspects to be considered are the post-harvest procedures, which are traditionally handmade at some steps in the production chain. Environmental conditions can also affect the moisture content $(m c)$ and water activity $(A w)$ of Brazil nut and provide conditions for aflatoxigenic fungi to produce aflatoxins (OLSEN et al., 2008). Therefore, the monitoring of these variables may support the decision-making during some processing stages ensuring product safety.

The production chain begins when the Brazil nut pods are collected after falling from the tress during the rainy season. The fruit pod is cracked open with a machete to remove the seeds, which are transported to the extractive sites where they are dehydrated. At this stage, dehydration is usually performed artisanally. Next, the nuts are bagged in raffia bags, or bulk nuts are stored in warehouses until they are transported to the processing plant by road or water. The aflatoxin contamination can occur in this step, mainly due to the influence of environmental conditions of storage and long distance transport. Therefore, the time elapsed between harvesting and processing should be as fast as possible (CENTRE..., 2008). Despite the procedures for monitoring the quality and safety of each plant with production flowcharts for specific demands, in general the process occurs as described in Figure 1. The process flowchart is described in Figure 1. It starts with the reception step, in which the nuts, of the same origin or from different locations, are tested for $m c(\max =15 \%)$ and $a w(\max =0.70)$, according to the legislation (BRAZIL, 2010). During this stage, the "cut" test is also performed, in which 100 nuts are evaluated for appearance (e.g., moldy, broken, dirty, stained, and empty). Each processing plant establishes the maximum amount of unacceptable nuts (e.g., 12\%). The "cut percentage" is going to define the material destination which includes the time and the drying temperature to which they will be submitted at a later stage since after reception, the batches are kept in warehouses for drying. The first sorting is performed by placing the dried nuts on a vibrating granulometric grid, in which they are sorted by size It is based on the "Brazil-nut effect" (ELLENBERGER; VANDU; KRISHNA, 2006; ROSATO et al., 1987), in which the

${ }^{1}$ Faculty of Pharmaceutical Sciences, Federal University of Amazonas - UFAM, Rua Comendador Alexandre Amorim, 330, Bairro Aparecida, CEP 69010-300, Manaus, AM, Brazil,e-mail: mary22on@hotmail.com

${ }^{*}$ Corresponding author 


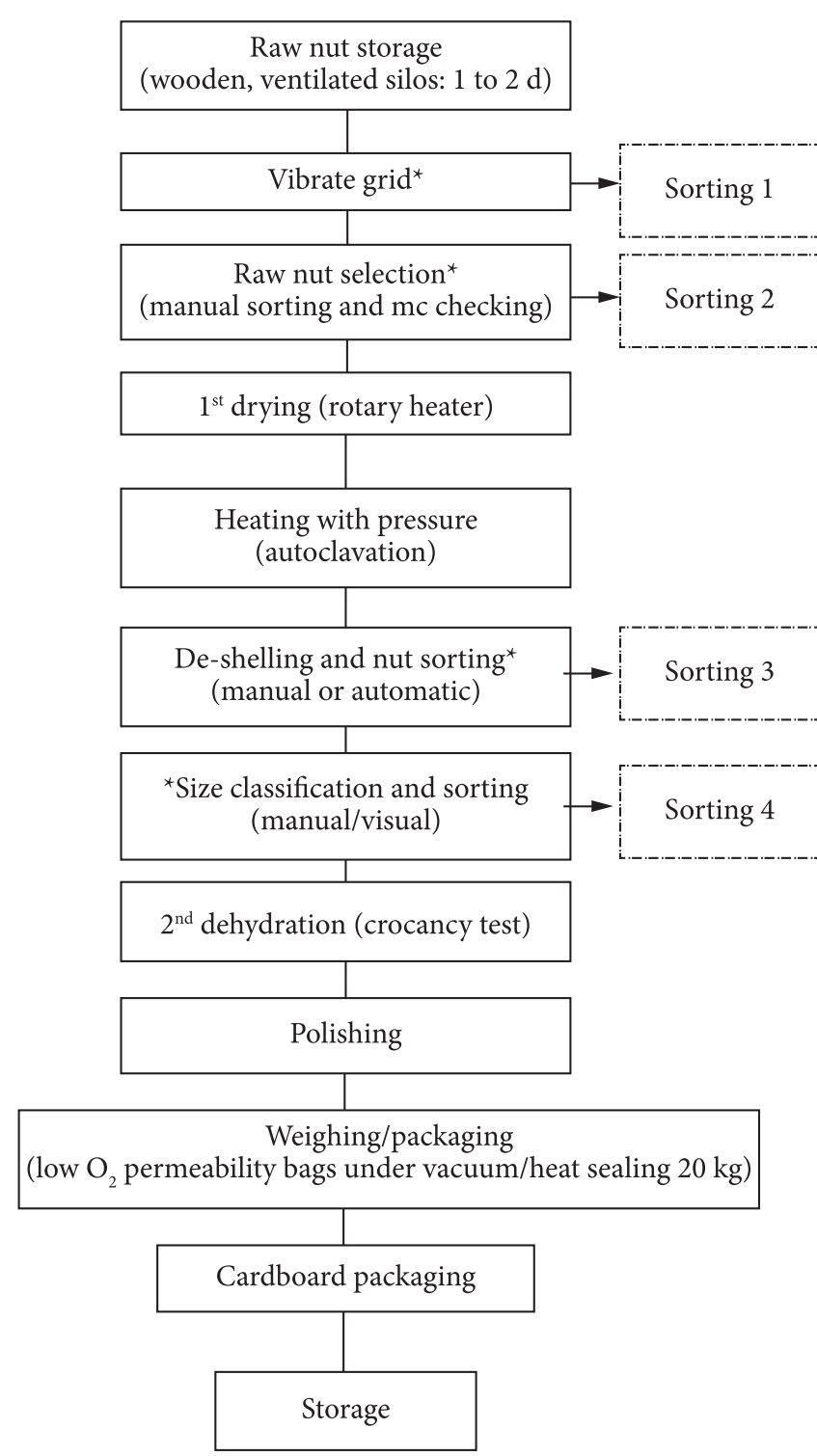

Figure 1. Flowchart of general shelled dry Brazil nuts processing with $\left[{ }^{*}\right]$ sorting steps.

larger size nuts rise to the top, and the smaller or empty nuts fall into the in the lower part of the apparatus. Following the visual/ manual sorting, performed by individuals trained to identify acceptable nuts, those considered unacceptable will be discarded. Manual and visual sorting of the defects of in-shell Brazil nuts seems to be efficient to reduce aflatoxin contamination to a certain extent, but it is only effective during nut cracking and shelling (STANDARDS..., 2009). The acceptance criteria are based on the visual aspect of the Brazil nut kernels classified as follows: good kernels; good shells, good nuts, rotten kernels, rotten shells, and rotten nuts (VARGAS et al., 2011).

In the next step, the nuts are dehydrated using a rotary dryer, when time and temperature will be defined according to the characteristics of the processing batches ( $m c$ and $A w$ ). After drying, the nuts are subjected to autoclaving for nutshell detachment facilitating shelling. Some nut processing plants use automatic shelling equipment; however, in other plants perform it manually, and the operator performs a new sorting of the shelled nuts considered as unacceptable. Shelled nuts obtained by either manual or automatic methods and are classified as Brazil nut in pieces and broken nuts, which will compose different batches. Then the nuts considered acceptable undergo a second dehydration process, in which the temperature and time will be determined by a test for crispness and moisture content of the material. Once the processing plants dehydration standard is reached, the nuts are classified by size (large, medium, small), in which manual/visual sorting of the unacceptable nuts is also performed. In this step, the nuts were weighed frequently to define the final batches according to the nut sizes. Subsequently, the nuts were weighed in $20 \mathrm{~kg}$ aluminum bags and were vacuum packed. The bags were packed in cardboard boxes and stored until shipment/sale. It is worth mentioning that Brazil nut processing involves many steps, so that inadequate handling can lead to considerable changes in their composition.

During Brazil nut processing, it is likely to occur loss of fatty acids and amino acids (SILVA; ASCHERI; SOUZA, 2010), but it is unclear if the binomial time/ temperature of the dehydration stages are significantly safe to prevent the production of aflatoxins (PACHECO et al., 2010).

During the processing of other kinds of nuts, the development of computerized systems and equipment for sorting has also been studied (JARIMOPAS; JAISINI, 2008; HAFF; PEARSON, 2007). According to De Mello and Scussel (2007), among the factors that may be considered for the use of automatic sorting are: weight, length, width, thickness, mc, Aw, and chromaticity.

However, visual/manual sorting of Brazil nut is a traditional step in its processing, which results in the creation of seasonal employment. The automatic sorting applicability needs to be evaluated since the high costs involved in its use could lead to inviability if there is a small scale production. On top of that, other studies have shown that computerized sorting showed no substantial improvement in the initial middium levels of contamination in peanuts batches, for example, which showed the widespread aflatoxin contamination (ZOVICO et al., 1999). Therefore, the efficiency evaluation in the sorting stages is important since in the case of other kinds of nuts these steps have shown the advantage of preventing contamination by aflatoxin. Concerning these aspects, it was necessary to study the impact of different methods for shelling Brazil nuts during the sorting stage including the variables: aflatoxin, $A w$, and $m c$.

\section{Materials and methods}

\subsection{Samples}

Different batches of Brazil nuts (2010 and 2011 harvests) were collected from a processing plant, in Brazil during the process stages, according to CAC (CODEX..., 2010). The samples were evaluated and collected in different stages of sorting as described in Figure 2: (a) inshell (before sorting 3), (b) shell, (c) shelled (sorting 3) and (d) pieces (sorting 4). The samples of 2010 harvest were obtained by the manual shelling 

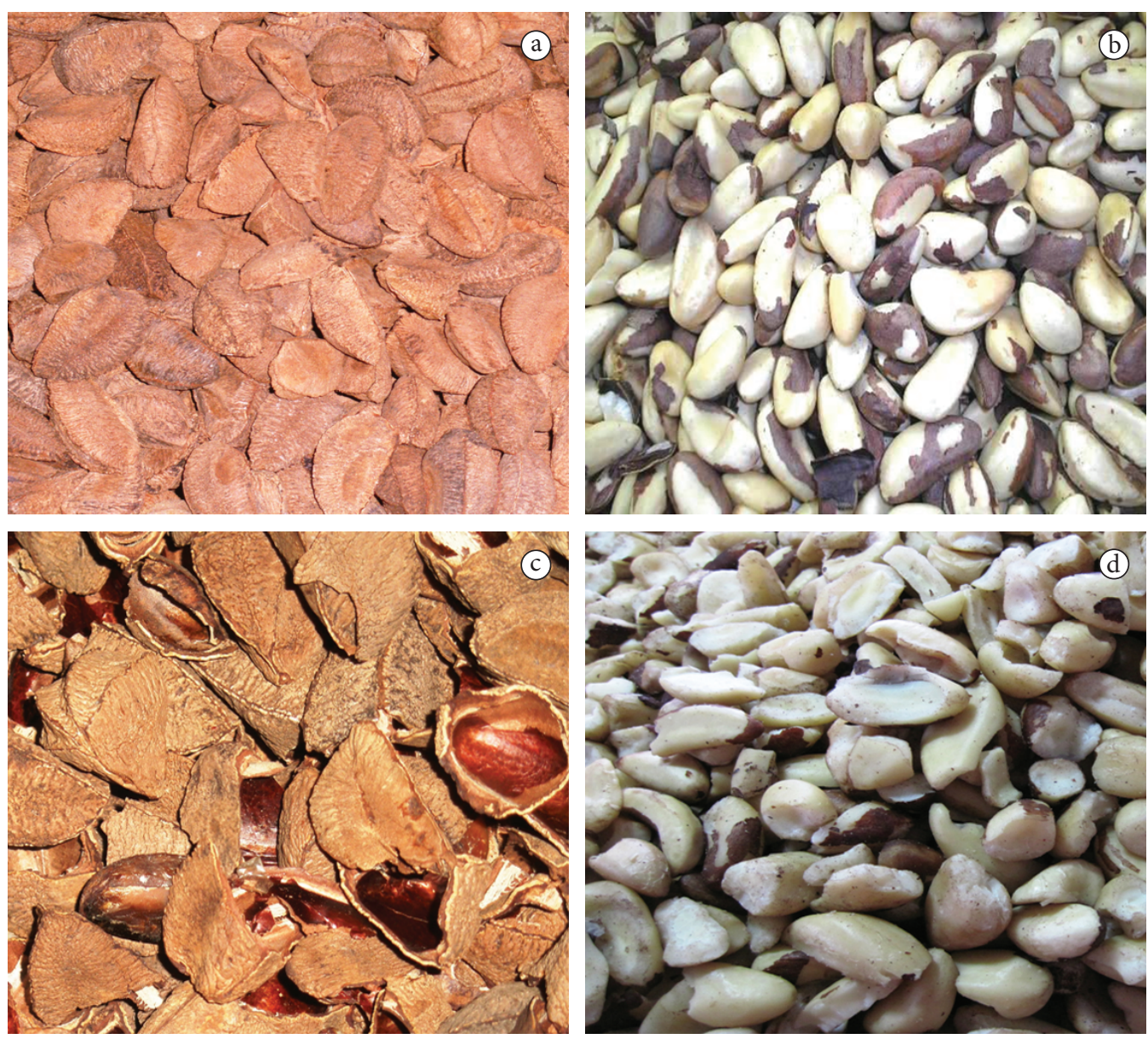

Figure 2. Brazil nut samples (a) In-shell; (b) Shelled; (c) shell; (d) Pieces.

method, but an automatic shelling method was adopted by the company before the sampling of 2011 harvest.

\subsection{Sample preparation}

The sampling method used was that required by the European Union (CODEX..., 2010). The samples were representatively collected during the processing, when incremental samples $(300 \mathrm{~g})$ were taken from each analyzed stage. They were homogenized, and final portions of $1 \mathrm{~kg}$ were packed and immediately sent to the laboratory. Frozen samples were finely ground (particle size $<100 \mu \mathrm{m}$ ) using a disk mill, homogenized, and portions of $500 \mathrm{~g}$ were transferred to lidded polyethylene containers with stored in a freezer. Portions of 50 and $25 \mathrm{~g}$ were used for aflatoxin analysis, in duplicate.

\subsection{Aflatoxins analysis}

The aflatoxin analysis was performed with LC-MS/MS with APCI in the positive mode (XAVIER; SCUSSEL, 2008). The LC conditions (C8 column) were mobile-phase methanol/ water gradient [ $45 \%$ water $/ 55 \%$ methanol ( 3 minutes); from 3 to 5 minutes, the gradient was changed to $30 \%$ water $/ 70 \%$ methanol] and flow rate of $1 \mathrm{~mL} / \mathrm{min}$. For MS/MS, 2 parentdaughter ion combinations $(\mathrm{m} / \mathrm{z})$ were selected for each toxin as follows: AFB1, $m / z 313.1$ (241.10 and 285.10); AFB2, $m / z 315$
(259.09 and 287.20); AFG1, $m / z 329.1$ (200.05 and 243.05); and AFG2, $m / z 331.2$ (245.07 and 231.20). The LOD and LOQ for LC-MS/MS of AFB1, AFB2, AFG1, AFG2 were $0.05,0.075,0.075$ and $0.1 \mu \mathrm{g} / \mathrm{kg}$ and $0.15,0.2,0.2 \mathrm{e} 0.3 \mu \mathrm{g} / \mathrm{kg}$ for each aflatoxin, respectively. The LOD and LOQ for total aflatoxin were 0.3 and $0.85 \mu \mathrm{g} / \mathrm{kg}$. To obtain those parameters, the finely ground Brazil nuts were homogenized and spiked prior to extraction with aflatoxins at five concentrations ranging from 1 to $10 \mu \mathrm{g} / \mathrm{kg}$. Portions of $25 \mathrm{~g}$ were taken for extraction adding $100 \mathrm{~mL}$ of acetonitrile/water $(80: 20, \mathrm{v} / \mathrm{v})$ to the sample; it was then mixed for 2 hours and filtered. The LOD method was defined by 3 times the signal-to-noise ratio, and the LOQ method was defined by 6 times the signal-to-noise ratio. Five points were used to build an analytical curve to obtain the $R$ values for LOD and LOQ. Each point corresponded to a mean of five injections of each extract. The recoveries for each aflatoxin (AFB1, AFB2, AFG1, AFG2) were 92.4, 72.5, 99.8, and 97.1\%, respectively. The shell/ nut ratio used for calculation was that reported by De Mello and Scussel (2007) of 60:40 (60\% shell/40\% nut), and the factor of 1.5 was considered the standard ratio for normal healthy whole Brazil nuts.

\section{$2.4 A w$}

The water activity (aw) was determined in triplicate in an Aqualab series $3 \mathrm{TE}$ instrument (Decagon, USA) at $25 \pm 0.1^{\circ} \mathrm{C}$. 


\subsection{Moisture content ( $\mathrm{mc}$ )}

The mc levels were determined by the gravimetric method (ASSOCIATION..., 2005).

\subsection{Statistical analysis}

To verify the normality of distributions, the Shapirowilk test was used, and to check homogeneity of variances, the Levene's test was used. The Student t-test was used for comparison between the levels of contamination among the different sorting stages. The comparison between the sizes was performed using analysis of variance (ANOVA). The coefficient of Pearson was used for correlation analysis.

\section{Results and discussion}

The data of aflatoxin contamination in different types of Brazil nut showed significant differences after the sorting stage. On the other hand, there was no evidence of significant differences concerning the manual or automatic shelling results obtained during the sorting stages, in terms of the variables. The correlation of $m c$ and $a w$ levels seem to be not enough to explain the aflatoxin contaminantion.

\subsection{Aflatoxins}

For the 2010 harvest samples (manual shelled) the mean (range), the levels of total aflatoxin were: in-shell $=14.9$ $(6.6-34.3) \mu \mathrm{g} / \mathrm{kg}$; shell $=15.0(3.0-60.3) \mu \mathrm{g} / \mathrm{kg}$; shelled $=1.11$ $(3.8-12.4) \mu \mathrm{g} / \mathrm{kg}$ and pieces $=3.0(8.0-13.1)$. For the 2011 harvest samples (automatic shelled) the average level for total aflatoxin was: in-shell = $7.7 \mu \mathrm{g} / \mathrm{kg}(7.0-21.2 \mu \mathrm{g} / \mathrm{kg}) ;$ shell $=13.6 \mu \mathrm{g} / \mathrm{kg}$ $(9.2-31.0 \mu \mathrm{g} / \mathrm{kg}) ;$ shelled $=1.6(2.0-9.30) \mu \mathrm{g} / \mathrm{kg}$, and pieces $=4.4$ (2.0-10.2) $\mu \mathrm{g} / \mathrm{kg}$. See Table 1 . The in-shell and shell samples, from both methods (manual and automatic shelling) had the highest aflatoxin levels, while the pieces and shelled samples had the lowest levels.

With regards to the decreasing of aflatoxin during the processing steps, sorting has proved to be an efficient method, according to the significant reduction of aflatoxin contamination found in the samples harvested throughout the procedure ( $p>0.0854)$. See Figure 2. However, although the visual/ manual sorting appears to be effective in preventing aflatoxin contamination in Brazil nuts, there is trend in the processing of nuts that should be considered, which is that the computerized equipment can efficiently perform sorting, and it has already been used for pistachio sorting. (OMID; MAHMOUDI; OMID, 2009). Therefore, it is important to point out that there have been attempts to develop physical and optical methods for the Brazil nut sorting using the following variables: size, color, density, and internal decay (DE MELLO; SCUSSEL, 2009). The level of aflatoxin contamination did not differ in the samples classified as shelled and pieces, and the latter showed the highest number of uncontaminated samples.

However, in the pieces samples, the aflatoxin concentrations were higher than those in the samples of shelled nuts. This can be explained by the fact that pieces batches are composed of nuts from which unacceptable parts were withdrawn (e.g. fungi, stains) and thus the probability of presence of aflatoxin would be greater.

In the present study, only samples classified as shelled from the 2011 harvest showed levels of aflatoxin contamination within the limits allowed by the European Community which are: $15 \mu \mathrm{g} / \mathrm{kg}$ in nuts intended for further processing and $10 \mu \mathrm{g} / \mathrm{kg}$ for "ready to eat" nuts. In fact, the contamination seems to be more associated with the shell (CODEX..., 2010), and the results are agree with those of Pacheco and Scussel (2009). It is possible that aflatoxins are concentrated in the shell and not in the nut, and after its removal the aflatoxin concentration can be reduced to levels below the lowest LOD value (CODEX..., 2010).

Another factor that may have affected the contamination is the drying temperature used in the process, which can also change the Brazil nut properties and composition (BONELLI et al., 2001). From another perspective, due to the fact that the shell is not edible, there is a reduced risk of contamination since deteriorated Brazil nuts may have features that are visually detectable by the consumer (e.g., visible mold, viscosity, low weight, discoloration, irregular shapes, and stirring

Table 1. Aflatoxin, $M c$, and $A w$ levels in manual shelled Brazil nut samples from the 2010 and 2011 harvests during different sorting stages.

\begin{tabular}{|c|c|c|c|c|c|c|c|c|c|c|}
\hline \multirow{2}{*}{$\begin{array}{c}\text { Harvest } \\
\text { types }\end{array}$} & \multicolumn{4}{|c|}{ Aflatoxin $^{\mathrm{a}}$} & \multicolumn{3}{|c|}{$M c$} & \multicolumn{3}{|c|}{$A w$} \\
\hline & Mean $^{\mathrm{b}}$ & Range $^{c}$ & $>10 \mu \mathrm{g} / \mathrm{kg}^{\mathrm{d}}$ & $>15 \mu \mathrm{g} / \mathrm{kg}^{\mathrm{d}}$ & Mean $^{\mathrm{a}}$ & Range $^{\mathrm{e}}$ & $>15 \%{ }^{\mathrm{f}}$ & Mean $^{\mathrm{a}}$ & Range $^{\mathrm{e}}$ & $>0,70^{g}$ \\
\hline \multicolumn{11}{|c|}{2010} \\
\hline In shell & $14.9 \pm 10.9$ & $6.6-34.3$ & 17 & 14 & $9.9 \pm 1.4$ & $7.0-12.3$ & 0 & $0.69 \pm 0.05$ & $0.6-0.80$ & 11 \\
\hline Shell & $15.0 \pm 12.5$ & $3.0-60.3$ & 18 & 14 & $8.5 \pm 1.1$ & $6.0-11.0$ & 0 & $0.61 \pm 0.04$ & $0.5-0.70$ & 0 \\
\hline Shelled & $1.1 \pm 2.7$ & $3.8-12.4$ & 1 & 0 & $2.1 \pm 0.3$ & $1.7-3.0$ & 0 & $0.60 \pm 0.03$ & $0.5-0.70$ & 0 \\
\hline Pieces & $3.0 \pm 3.9$ & $8.0-13.1$ & 2 & 0 & $2.2 \pm 0.3$ & $1.6-2.9$ & 0 & $0.59 \pm 0.11$ & $0.5-0.70$ & 0 \\
\hline Shell & $13.6 \pm 6.7$ & $9.2-31.0$ & 26 & 10 & $7.9 \pm 2.3$ & $4.9-12.9$ & 0 & $0.40 \pm 0.65$ & $0.49-0.70$ & 0 \\
\hline Shelled & $1.6 \pm 2.4$ & $2.0-9.30$ & 0 & 0 & $2.7 \pm 0.8$ & $1.6-4.9$ & 0 & $0.57 \pm 0.07$ & $0.48-0.70$ & 0 \\
\hline Pieces & $4.4 \pm 2.6$ & $2.0-10.2$ & 1 & 0 & $1.9 \pm 0.7$ & $1.0-4.0$ & 0 & $0.61 \pm 0.08$ & $0.49-0.71$ & 0 \\
\hline
\end{tabular}

Note: ${ }^{a}$ total aflatoxin $(\mathrm{B} 1+\mathrm{B} 2+\mathrm{G} 1+\mathrm{G} 2)$; ${ }^{\mathrm{b}}$ mean \pm standard deviation; ${ }^{\mathrm{c}}$ mplitude of the concentration of total aflatoxins in the LOQ for Total Aflatoxin; ${ }^{\mathrm{d}}$ relative frequency of samples with concentrations above the European limits for total aflatoxin; ${ }^{\mathrm{e}}$ amplitude; frelative frequency of samples with concentrations above the limits for $m c$ in Brazil nuts; ${ }^{\mathrm{g}}$ relative frequency of samples with concentrations above the limits for $A w$ in Brazil nuts. 
nut in the shell). Such characteristics can facilitate the sorting process of damaged nuts (MARKLINDER et al., 2005).

In general, the difference in aflatoxins levels in the analyzed samples can be partly explained by the fact that the batches of nuts are composed of different origins and characteristics and in spite of undergoing the same drying procedures, they might have already had a certain level of contamination of their own.

\subsection{Mc and Aw}

The average (range)\% of $m c$ levels in the samples were: (a) 2010 harvest: in -shell $=9.90(7.0-12.3) \%$, shell $=8.5(6.0-11.0) \%$, shelled $=2.1$ (1.7-3.0)\%, and pieces $=2.2(1.6-2.9) \%$; (b) 2011 harvest: in-shell $=9.2(6.6-12.2) \%$, shell $=7.9(4.9-12.9) \%$, shelled $=2.7(1.6-4.9) \%$ and pieces $=1.9(1.0-4.0) \%$. In the present study, all samples showed $m c$ levels below the limit of 15\% (BRAZIL, 2010; CODEX..., 2010) (Figure 3). In another study, Johnsson et al. (2008) concluded that the RH\% and temperature were significant factors that influenced the $m c$ and $A w$ variables, fungal proliferation, and aflatoxins production. However, the results obtained in the present study are not explanatory to relate the $\mathrm{mc}$ in the samples studied during processing because the aflatoxin contamination may have occurred even before harvest.

Storage is considered another critical step because depending on its duration and conditions, it can cause fungal growth and aflatoxin production. The time between extraction/ collection and transport to the processing plants is done either by boats or trucks and may take up 50 days in environments with $\mathrm{RH} \%$ above $70 \%$.

With regards to the variables' temperature and $\mathrm{RH} \%$ of the Amazon region, short time storage should be applied (PACHECO et al., 2010).

Another factor that may facilitate the spread of aflatoxigenic fungi in Brazil nuts is the mechanical damage that may occur in the forest and during transport. Although Arrus et al., (2005b) have detected the presence of aflatoxigenic strains with no aflatoxin production in forests' pods during their fall from the trees and cutting, during the transport, and in the plants during the processing steps; the damages may favor moisture absorption and facilitate the invasion and penetration of fungal spores. Brazil nuts are highly nutritious and can offer substrate for the development of fungi and consequently the production of toxins. There were no correlations observed between the parameters $m c$ and $a w$ (Figure 4). This can be explained by the use of diferente batches, containing nuts of different origins and different characteristics, during the various stages of processing since the temperatures used should decrease proportionally with the decrease in $m c$ and $a w$. According to Arrus et al., (2005a), despite the accuracy of the $a w$ meter $(70.01 \%)$, the variation between these values could have resulted in slight differences in $m c$ beween the nuts, which were kept under controlled RH since different nuts were used to determine $m c$ and $a w$. Such process can also cause changes in the chemical composition of the nutrients present in the nuts or physical defects (e.g. cracks) in nuts, such as the case of accelerated desorption of the drying process. Only the in-shell samples from both harvest periods showed levels of $a w$ above the limit of 0.70 .

According to Arrus et al. (2005b), the Aspergillus flavus strains proved to be highly influenced by the combination of $\mathrm{pH}$ and $a w$ at specific temperatures, in terms of the aflatoxins production. It is recommended that the nuts are kept at levels of $a w<0.70$ right after harvest, and that damaged/deteriorated nuts must be sorted out in order to reduce contamination (CENTRE..., 2008).

\subsection{Effect of Manual/automatic shelling on sorting}

There were no significant differences between the manual or automatic shelling methods in terms of aflatoxin contamination. On the other hand, sorting during different stages of the Brazil nut processing seems to be effective in decreasing the aflatoxin levels.

At the Brazil nut processing plant, some Good Manufacturing Practices (GMPs) and HACCPs, such as the control of RH\%, temperature and traceability of the nuts to avoid the damaged ones must be observed to prevent the aflatoxin contamination in nut pieces.

With regards to the sorting step, the subjective aspect of the operators' performance could be considered as a limiting factor for the manual/visual method. During this activity, constant training, health condition, or individual exhaustion due to
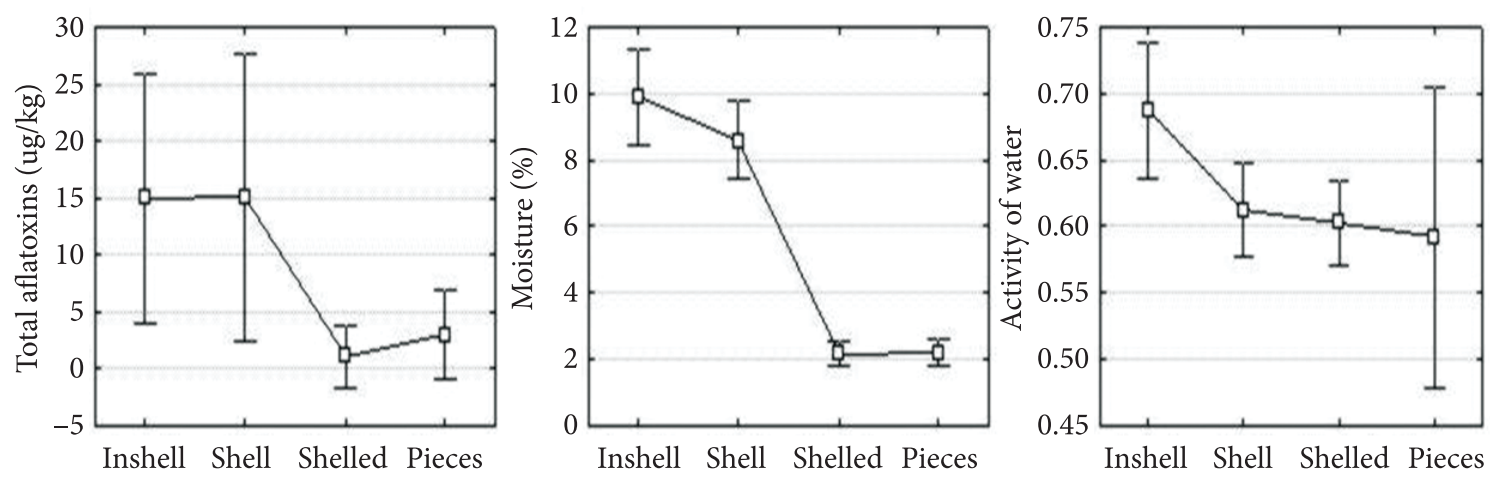

Figure 3. Mean and standard deviation of variables studied during the processing of the Brazil nut. 

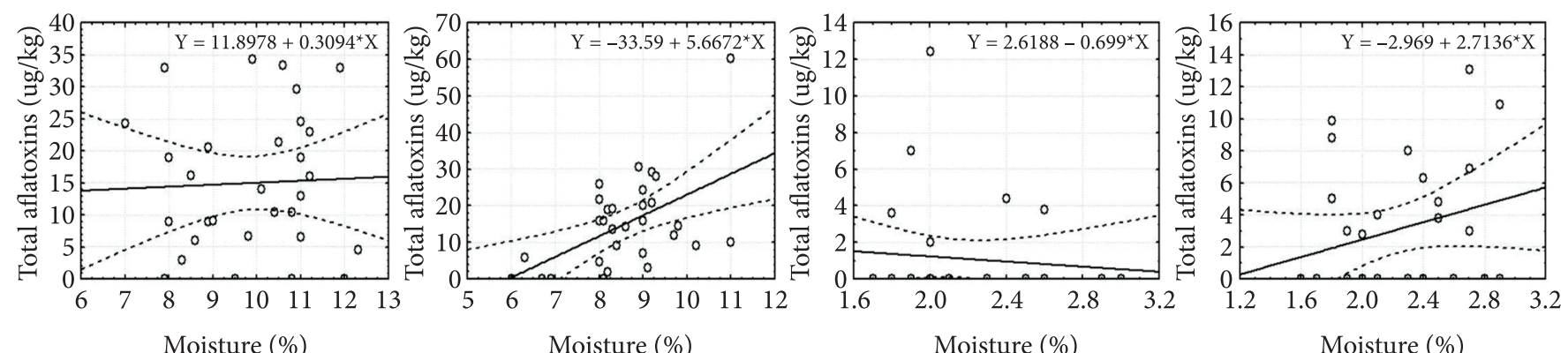

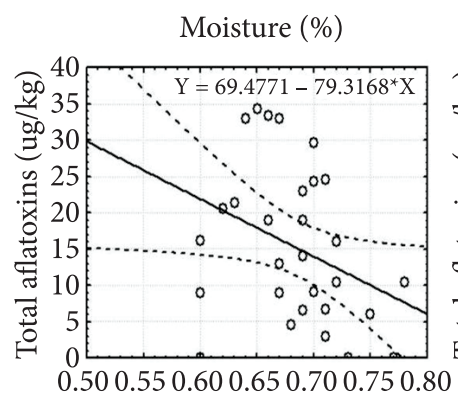

Activity of water

Inshell

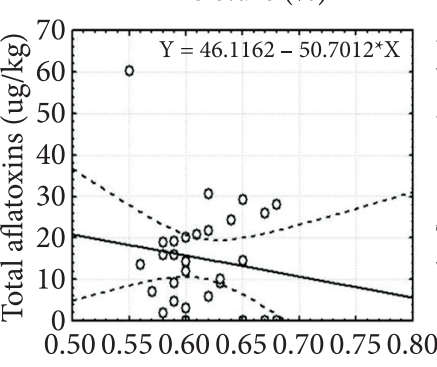

Activity of water

Shell

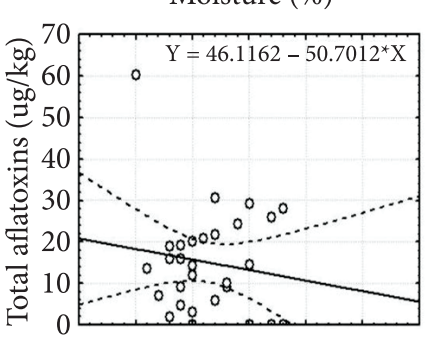

Activity of water

Shelled

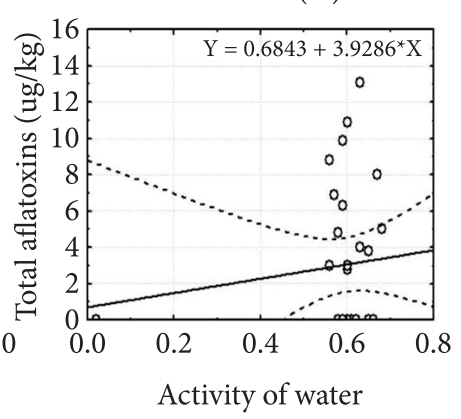

Pieces

Figure 4. Points of dispersion, equation correlation between the independent variables, moisture and water activity, and total aflatoxin for each sample type.

working time should be taken into account since they may affect performance and allow the inclusion of unacceptable nuts.

Therefore, conditions that facilitate/enhance manual sorting have been tested. Steiner et al. (1992) evaluated aflatoxin contamination by means of fluorescence and found that contaminated pistachios showed no fluorescence. On the other hand, the Brazil nuts showed fluorescence without being contaminated. The vibration on the track during sorting is another factor that may affect the sorting performance.

However, the "Brazil nut effect", seems to be questionable because according to Metzger, Remy and Glasser, 2011, some larger nuts do not remain in the top. This fact could affect the ranking by size and the homogeneous drying of the batches due to the presence of nuts of different sizes, even in small quantities.

\section{Conclusions}

The visual/ manual sorting was effective in the prevention of aflatoxin during Brazil nut processing regardless of the shelling methods. These results can indicate that the product can be considered safe when facing the tolerance limits for aflatoxins in different countries. Further research is highly suggested to evaluate the effect of damage to the nuts on the physicochemical properties, not only during post-harvest period but also during processing, relating them to the aflatoxin level. Another aspect would be the use of other physical methods for sorting besides the UV light method. The efficiency of different drying temperatures to obtain homogeneous batches and safe levels of aflatoxins, as well as the influence of these temperatures on the final product and its antioxidant properties are important variables to be considered. It would be also important to study sorption isotherms for the Brazil nut processing in order to improve the quality of the nuts.

\section{References}

ASSOCIATION OF OFFICIAL ANALYTICAL CHEMISTS - AOAC. Official Methods of Analysis of the 18th International AOAC. Gaithersburg: AOAC, 2005

ARRUS, K. et al. Microbiological and aflatoxin evaluation of Brazil nut pods and the effects of unit processing operations. Journal of Food Protection, v. 68, n. 5, p. 1060-1065, 2005a. PMid:15895742.

ARRUS, K. et al. Aflatoxin production by Aspergillus flavus in Brazil nuts. Journal of Stored Products Research, v. 41, p. 513-527, 2005 b. http://dx.doi.org/10.1016/j.jspr.2004.07.005

BONELLI, P. R. et al. Effect of pyrolysis temperature on composition, surface properties and thermal degradation rates of Brazil nut shells. Bioresource Technology, v. 76, n. 1, p. 15-22, 2001. http://dx.doi. org/10.1016/S0960-8524(00)00085-7

BRAZIL. Ministry of Agriculture, Livestock and Supply. Instruction Normativ no 11, 22 march 2010. Criteria and Procedures for the control hygiene and health the Brazil nut and its by products. Diário Oficial da República Federativa do Brasil, Brasília, DF, 23 mar. 2010.

CENTRE DE COOPÉRATION INTERNATIONALEENRECHERCHE AGRONOMIQUE POUR LE DÉVELOPPEMENT - CIRAD. Validation and transfer to the key stakeholders of a sustainable and effective aflatoxin management system in the Brazil nut production chain for recovering and consolidating export markets, particularly in Europe. CIRAD, 2008. STDF 114. Final Report.

CODEX ALIMENTARIUS COMMISSION - CAC. Report of the Fourth Session of the Codex Committee on Contaminants in Foods. Izmir, Turkey, 2010. CL 2010/13-CF.

COSTA, P. A. et al. Phytosterols and tocopherols content of pulps and nuts of Brazilian fruits. Food Research International, v. 43, n. 6, p. 1603-1606, 2010. http://dx.doi.org/10.1016/j.foodres.2010.04.025 http://dx.doi.org/10.1016/j.foodres.2010.04.025 
DE MELLO, F. R.; SCUSSEL, V. M. Development of Physical and Optical Methods for In-shell Brazil Nuts Sorting and Aflatoxin Reduction. Journal of Agricultural Science, v. 1, n. 2, p. 3-14, 2009.

DE MELLO, F. R.; SCUSSEL, V. M. Characteristics of in-shell Brazil nuts and their relation to aflatoxin contamination: Criteria for sorting. Journal of Agricultural and Food Chemistry, v. 55, p. 9305-9310, 2007. PMid:17924705. http://dx.doi.org/10.1021/ jf071392x

ELLENBERGER, J.; VANDU, C. O.; KRISHNA, R. Vibration-induced granular segregation in a pseudo-2D column: The (reverse) Brazil nut effect. Powder Technology, v. 16, p. 168-173, 2006. http://dx.doi. org/10.1016/j.powtec.2006.03.012

HAFF, R. P.; PEARSON, T. C. An automatic algorithm for detection of infestations in X-ray images of agricultural products. Sensonry and Instrumentation for Food Quality, v. 1, p. 143-150, 2007. http:// dx.doi.org/10.1007/s11694-007-9018-9

INSTITUTO BRASILEIRO DE GEOGRAFIA E ESTATÍSTICA - IBGE. Production of plant extraction and forestry. IBGE, 2010. Disponível em: <http://www.ibge.gov.br/home/estatistica/ economia/pevs/2010/pevs2010.pdf>. Acesso em: 27 dez. 2011.

JARIMOPAS, B.; JAISIN, N. An experimental machine vision system for sorting sweet tamarind. Journal of Food Engineering, v. 89, p. 291-297, 2008. http://dx.doi.org/10.1016/j.jfoodeng.2008.05.007

JOHNSSON, P. et al. Growth of aflatoxigenic moulds and aflatoxin formation in Brazil nuts. World Mycotoxin Journal, v. 1, n. 2, p. 127-137, 2008. http://dx.doi.org/10.3920/WMJ2008.1033

MARKLINDER, I. et al. Consumer's ability to discriminate aflatoxin-contaminated Brazil nuts. Food Additives \& Contaminants, v. 22, p. 56-64, 2005. PMid:15895612. http://dx.doi. org/10.1080/02652030400028043

METZGER, M. J.; REMY, B.; GLASSER, B. J. All the Brazil nuts are not on top: Vibration induced granular size segregation of binary, ternary and multi-sized mixtures. Powder technology, v. 205, n. 1-3, p. 42-51, Jan 2011. http://dx.doi.org/10.1016/j.powtec.2010.08.062

OLSEN, M. et al. Aspergillus nomius, an important aflatoxin producer in Brazil nuts? World Mycotoxin Journal, v. 1, n. 2:123-126, 2008. http://dx.doi.org/10.3920/WMJ2008.1032

OMID, M.; MAHMOUDI, A.; OMID, M. H. An intelligent system for sorting pistachio nut varieties. Expert Systems
With Applications, v. 36, p. 11528-11535, 2009. http://dx.doi. org/10.1016/j.eswa.2009.03.040

PACHECO, A. M. et al. Association between aflatoxin and aflatoxigenic fungi in Brazil nut (Betholletia excelsa H.B.K.. Food Science and Technology, v. 30, n. 2, p. 1-6, 2010.

PACHECO, A. M.; SCUSSEL, V. M. Aflatoxins evaluation on inshell and shelled dry Brazil nuts for export analyzed by LC-MS/ MS - 2006 and 2007 harvests. World Mycotoxin Jounal, v. 2, n. 3, p. 295-304, 2009. http://dx.doi.org/10.3920/WMJ2008.1077

ROSATO, A. et al. Why the Brazil nuts are on top: size segregation of particulate matter by shaking. Physical Review Letters, v. 58, n. 10, p. 1038-1040. 1987. PMid:10034316. http://dx.doi.org/10.1103/ PhysRevLett.58.1038

SILVA, R. F.; ASCHERI, J. L. R.; SOUZA, J. M. L. Influence of the process of processing of the Brazil nut in the quality of the beans. Science Agrotecnol, v. 34, n. 2, p. 445-450, 2010. http://dx.doi.org/10.1590/ S1413-70542010000200025

STANDARDS AND TRADE DEVELOPMENT FACILITY - STDF. STDF 114: Project SafeNut - Final report covering period from 1 June 2006 to 30 November 2008 - Project: 'Validation and transfer to the key stakeholders of a sustainable and effective aflatoxin management system in the Brazil nut production chain for recovering and consolidating export markets. particularly in Europe' - Project coordinators: Catherine Brabet. CIRAD, France - General Coordinator Monica OLSEN. Sweden: Scientific Coordinator Last version, May 2009.

STEINER, W. E. et al. Aflatoxins and fluorescence in Brazil nuts and Pistachio nuts. Journal of Agricultural and Food Chemistry, v. 40, p. 2453-2457. 1992. http://dx.doi.org/10.1021/jf00024a022

XAVIER, J. J. M.; SCUSSEL, V. M. Development of an LC-MS/MS method for the determination of aflatoxins B1, B2, G1, and G2 in Brazil nut. Journal of Agricultural and Food Chemistry, v. 88, p. 425-433, 2008.

VARGAS, E. et al. Determination of aflatoxin risk componentes for in-shell Brazil nuts. Food Additives and Contaminants, v. 28, n. 9, p. 1242-1260, 2011. PMid:21838597. http://dx.doi.org/10.1080/19 440049.2011 .596488

ZOVICO, C. et al. Electronic color sorting in the decontamination of peanuts contaminated withaflatoxins. Scientia Agricola, v. 56, p. 371-376. 1999. http://dx.doi.org/10.1590/S010390161999000200016 